\title{
Crisis! What Crisis?
}

\section{Robert L. Flood ${ }^{1}$}

Published online: 1 February 2021

(C) The Author(s), under exclusive licence to Springer Science+Business Media, LLC part of Springer Nature 2021

"The destiny of humans cannot be separated from the destiny of Earth." Thomas Berry (2015)

I began my undergraduate degree in 'Systems and Management' at City University, London, in 1979. Of the many course books that I read in the first year, two stand out above all others: The Limits to Growth by the Club of Rome, and Tools for Thought by Conrad Hal Waddington.

Limits presents system dynamics model simulations of exponential economic and population growth and some of the possible consequences of this, such as resource depletion, food shortages, waste mountains, and ultimate collapse. By today's standards, the model, and the computer power to drive the model, respectively, were simple and primitive, but the message was profound. There were many disparaging criticisms of Limits, about it being simplistic, not considering human ingenuity to solve problems 'on the go', and that the models were a poor representation of reality. Of course, models of that era and even of today cannot precisely represent and simulate the consequences of human activity. However, the critics miss the fundamental point of it all, that growth cannot go on forever, that there must be some limits, and that this is no more than common systemic sense.

Tools presents the scientific techniques of its time in a readily understandable fashion and was quite suited, for example, to a first-year undergraduate student. Its focus is complexity and dealing with complexity, with a focus on cybernetics and systems. Tools engaged with Limits in a highly constructive fashion, addressing the 'complex of complexes' and the difficulties in knowing which interactions to model, how these interactions change over time, and the uncertainties in model outcomes. BUT it stressed that the models help us to learn about types of behaviour that might happen, possible outcomes, and that these behaviours and outcomes are further ingredients for thought, not failings of a model. More than anything else, though, Waddington's dislike of the conventional wisdom of the dominant group, or, as he phrased it, COWDUNG, resonated strongly with my thoughts - a dislike for the unquestioning adherence to convention.

Robert L. Flood

robertlouisflood@gmail.com

1 Norwegian University of Science and Technology, Trondheim, Norway 
Convention engaging with critique could make a healthy collaboration. Convention, however, does not engage with critique, indeed it resists it, and resists with might. So, here we are in the modern day, 40 years on from my undergraduate years, COWDUNG still prevails, and we are facing the same fundamental problem - the limits to growth and the need for adequate tools for thought. Predictions in Limits may not have been exact, or fall in the given timescale, but now we can see that the kinds of behaviour and outcome generated by the models were more than mildly prophetic. Even so, the convention of growth continues, and continues in the various forms of capitalism, communism, and most other economic isms as practiced worldwide. The way of dealing with the problems of growth, we are told, is more of what caused the problems of growth in the first place... I hold my head in despair.

There is cause for optimism. In the past 40 years the resistance to COWDUNG has grown. We now have sophisticated systemic appreciations of social, technical, and environmental issues, and a diversity of systemic methods by which to address them, as evidenced in Mixed Methods and Cross Disciplinary Research (McIntyre-Mills and Romm 2019) and From Polarisation to Multispecies Relationships (McIntyre-Mills and Corcoran-Nantes 2021). Equally heartening are the increasingly potent global people grassroots movements. The combination of grassroots people power and systemic tools for thought coming from professional communities promises to combine to challenge and bring about change to the practices of COWDUNG. The combination provides the opportunity for change and the tools to facilitate change.

"As humans we are born of the Earth, nourished by the Earth, and healed by the Earth."

Thomas Berry (2015)

There are many pressing issues to tackle but, to my mind, a fundamental issue in all of this is the need to redress our understanding of the relationship between humankind and the natural world. COWDUNG has it that humankind is somehow distanced even separated from the natural world, the natural world is a resource to be exploited by humankind, and it is fine that the result is a worldwide humanscape.

The kind of humanscape that we are creating involves a mass extinction event. We are witnessing the early stages of mass extinction in the squeezing out of the mega-fauna of the open plains, the mega-fauna of the oceans, and the mega-forests with their great diversity of wildlife.

One could ask, 'Does this really matter?' After all, there have been five mass extinction events over the past 450 million years. To boot, the head of NASA SETI, NASA's search for extra-terrestrial intelligence, during a lecture that I attended in the early 1980 s, pointed out that over $99.9 \%$ of all species that have lived on Earth are now extinct. So, is there really, really a problem with the current human-driven mass extinction? Well, yes, there are several deadly problems.

For a start, when part of an ecosystem is extinguished, the cycle of life is broken, and the ecosystem collapses. It is a simple systemic fact. Here is a good example. New sources of food are needed to feed the ever-growing human population. The fishing industry has identified krill as abundant and offering fatty acids and other nutrients suited to the human diet. Krill are small crustaceans found across the world's oceans and are particularly abundant in cool waters such as around Antarctica. Consequences if harvested in moderation may not be a great worry, but excessive localised harvesting, which evidence indicates may have already happened, will break the food chain and the whole ecosystem that incorporates the krill will collapse because there is no food for creatures positioned higher up the food chain. Consequently, we lose krill, fish, dolphins, whales, and seabirds. 
The fishing industry is notorious for thoughtless unnecessary harm that it causes to ocean wildlife. Fisheries once targeted tuna using nets without regard for other wildlife and consequently killed thousands of dolphins. People protest stopped this practice, but the fishing industry then blundered forward, switching to longline fishing. Longline bycatch involves $10 \mathrm{~s}$ of thousands of albatrosses and petrels attracted by bait attached to the hooks, but albatrosses and petrels become hooked and drown as the line sinks and drags them under. Of 25 albatross taxa, 21 of them are threatened with extinction. 'Save the Albatross' campaign is attempting to educate the industry worldwide with mitigation techniques, but even if the campaign is successful, a third of the world's longline fishing remains illegal and out of control.

Some exploited ecosystems survive, at least in one form or another, though with a muchreduced biodiversity. The World Health Organisation recognises that biodiversity plays a crucial role in human nutrition as it is necessary for food production by ensuring productivity of soils and protection of the genetic diversity necessary for nature to remain in balance. Reducing biodiversity creates 'more of less', larger numbers of fewer species, and is playing a dangerous game with the balance of nature and, as systemic models indicate, in such circumstances the behaviour and outcomes are extremely uncertain. In human food production, it creates the opportunity for disease to run rampant and destroy a monoculture like a wheat crop that feeds millions of people. Play with the balance of nature and nature tends to kick back.

The 2020/21 Covid 19 crisis is a systemic warning, a warning of the highest order, that the humanscape that COWDUNG is creating on Earth is something that the balancing forces of nature will have a say on. Population explosions of species are always moderated by nature; by starvation when populations become too large for available/potential food availability/supply, or by disease, or by both. As said in Limits in the 1970s, there are limits to growth.

"If we lived on the moon, our minds and emotions, our speech, our imagination, and

sense of the divine would be limited to the lunar landscape." Thomas Berry (2015)

There is another kind of consequence of mass extinction, one that penetrates deep into our very being. Human beings are not aliens transported to Earth. Human beings are of Earth, emerging as a species on Earth over millions of years, made up from and made viable by the elements and systemic processes of Earth. The single most important recognition given to me by Thomas Berry (e.g. 1981, 2009, 2015) is that each one of us humans as a self-aware being is a formation of the Universe looking at the Universe. We are indeed the Universe looking at itself. The human psyche, the human spirit, the emotional health of humans, will be diminished in equal or greater scale than the rapidly diminishing diversity in life and systemic processes that formed and support us. It is a process of dehumanisation. Mental well-being and the human spirit cannot be sustained as the diversity of nature that gave birth to us becomes ever more like a lunar landscape; as we replace diversity with uniformity, living processes with inanimate structures, and lose touch with the natural world of which we are an integral part.

Losing touch with the natural world happens, not just by destroying it, but also by distancing ourselves from it, by relocating ourselves to a virtual world, by trivialising and masking the fate of the natural world. Dwell for a moment on the following example. Orangutans have no future in the wild as their home, the mega-forest of Borneo, is logged from coast to coast. Yet, with sickening irony, in the UK an Orangutan is used in a TV advert to promote an energy company. Under the banner 'Seeing energy through fresh eyes' we 'See Maya, the majestic Orangutan...' - here trivialised with a human name - '...make her way from the rainforest into our urban world.' The fate of the natural world is masked by false 
images of a healthy rainforest, but there is little rainforest left in much of Borneo and consequently few Orangutans. The nature of Orangutans is wrongly portrayed. Orangutans do not think like humans and Orangutans do not belong in the human urban world. The degree of ignorance in the advert is astounding and scary.

And a final thought. Solutions to resource shortage include mining resources on other planets and colonising Mars. Such ideas, once the fantasy of boffins and eccentrics, are today technologically feasible and part of the future strategy of COWDUNGers. Bringing resources to Earth does not solve the problem of a human population growing out of control; transporting some of the population to Mars does not solve the problem of killing the human psyche and spirit. The human psyche and spirit have not fared well in the Covid 19 crisis during lockdown. Easing of restrictions, for example, in England in the summer of 2020, led to a rush to the countryside and coastal regions as people knowingly or unawares reconnected with the natural world. So, how would the human psyche and spirit fare if our minds and emotions, our speech, our imagination, and sense of the divine were limited to the Martian landscape?

Adapted from an article of the same name in McIntyre-Mills and Corcoran-Nantes (2021).

\section{References}

Berry T (1981) Spirituality and Ecology. Presentation and Reflections Delivered at the Cathedral of St John the Divine in New York City. http://thomasberry.org/publications-and-media/spirituality-andecologynovember-8-1981. Accessed 20 Feb 2020

Berry T (2009) The Sacred Universe: Earth, Spirituality and Religion in the 21st Century. Columbia University Press, New York

Berry T (2015) The Dream of the Earth. Reprint Counterpoint, Berkeley

McIntyre-Mills J, Corcoran-Nantes Y (2021) From Polarisation to Multispecies Relationships. Springer, New York

McIntyre-Mills J, Romm NRA (2019) Mixed Methods and Cross Disciplinary Research: Towards Cultivating Eco-Systemic Living. Springer, New York

Publisher's Note Springer Nature remains neutral with regard to jurisdictional claims in published maps and institutional affiliations. 